\title{
Disputas caballerescas en la Córdoba bajomedieval. El riepto entre Don Alonso de Aguilar y el Mariscal don Diego de Cabra
}

\author{
Gonzalo Oliva Manso \\ Doctor en Historia Medieval, UNED
}

\begin{abstract}
RESUMEN
El enfrentamiento entre el Mariscal don Diego de Cabra y don Alonso de Aguilar constituye la última referencia al riepto judicial que conservamos en nuestras fuentes. Este riepto no es un hecho aislado por cuanto se encuentra inmerso dentro de un conflicto general que enfrenta a ambos personajes y a sus familias por el control de la zona cordobesa. La negativa real a la tramitación del riepto motivará la transformación de la disputa, perdiendo sus aspectos jurídicos y deviniendo plenamente caballeresca. El desarrollo del desafío mostrado a través del intercambio epistolar sigue los convencionalismos propios en estos aconteceres culminando con la celebración de sendos espectáculos con los que cada uno de los contendientes pretende aparecer ante la opinión pública como vencedores del
\end{abstract} conflicto.

\section{PALABRAS CLAVE}

Riepto, desafio, pugna duorum, Córdoba, Fernández de Córdoba.

\begin{abstract}
The quarrel between the Marshal don Diego de Cabra and don Alonso de Aguilar represents the last citation that we maintain in our sources about the legal challenge. This challenge is not an isolated event, as it is in the context of a general conflict that face up both knights and their families, to control the area of Cordoba. The royal denial to approve the challenge administrative procedure, will motivate the transformation of the challenge, loosing its legal aspects and becoming completely knightly. The challenge development, shown through an epistolary interchange, follows the particular conventionalisms of these course of events, culminating with the celebration of both performances, with which each one of the contenders aims to appear in the face of the public opinion as if they were the winners of the conflict.
\end{abstract}

\section{KEY WORDS}

Riepto, challenge, pugna duorum, Córdoba, Fernández de Córdoba. 
El 27 de mayo de 1470 don Diego de Córdoba firma una carta por la que riepta a don Alonso de Aguilar por el prendimiento irregular, no había sido precedido del necesario desafío, de su propia persona. Nos encontramos con los estertores finales, no tenemos huellas de ningún riepto posterior, de una institución que acompañó todo el fluir de la Edad Media hasta sus últimos momentos. Lejos quedan los tiempos en los que a través de él Diego Ordóñez trataba de vengar el asesinato de Sancho II que había manchado la reputación de sus vasallos castellanos, y Rodrigo, el de Vivar, intentaba resoiver sus propios conflictos: afrentas personales o acusaciones de traición. En estos instantes finales del medievo castellano el riepto había quedado no olvidado pero sí muy deformado y trufado de elementos caballerescos por cuanto hacía mucho tiempo que los reyes no daban lugar a su realización que inevitablemente y conociendo la belicosidad de sus nobles sabían degeneraria en combate singular; por estas mismas razones tampoco permitian que las deshonras entre ellos terminaran por concluir en un combate caballeresco.

A su condición de último ejemplo del riepto en Castilla nos mueve a su estudio el tratamiento parcial que de los hechos, en menoscabo de don Alonso de Aguilar, se ha venido reflejando en diversos estudios sobre la historia municipal de las localidades de los contendientes, Córdoba ${ }^{1}$ y Cabra $^{2}$, así como en las crónicas de la época, en las que se basan las anteriores. Esta parcialidad se ha dado por el uso de unas fuentes tendenciosas, proclives siempre a la causa de don Diego de Cabra, personaje cercano a Enrique IV ${ }^{3}$. Las dos crónicas sobre su reinado fueron realizadas por personas afines a su causa y, por tanto, resaltaron cuantos hechos consideraron precisos para el engrandecimiento de los aliados regios y en menoscabo de los nobles rebeldes, a lo que hay que añadir que hemos conservado sólo las cartas emitidas por parte del Mariscal don Diego ${ }^{4}$. Frente a todo ello úni-

R. Ramirez de Arellano, Historia de Córdoba IV, Ciudad Real, 1920.

N. Albornoz y Portocarrero, Historia de la ciudad de Cabra, Madrid, 1909.

Esta mezcolanza de elementos caballerescos y políticos ya habia aparecido en otros casos como en la defensa del Paso del río Órbigo por Suero de Quiñones. Si en este último acudieron a retarle un número considerable de caballeros cercanos al rey de Aragón (Vid. M. de RIQuER, Caballeros andantes españoles, Madrid, 1967, 97-99.), ahora los implicados representan las dos facciones de la politica castellana contemporánea.

${ }^{4}$ D. Enriquez del Castillo en su Crónica de Enrique IV, BAE 70, Madrid, 1953, pp. 193-194, nos ofrece un relato breve de todo el desarrollo del asunto donde destaca la presencia integra de la carta que don Diego envió al monarca reptando como aleve la conducta de don Alonso, soslaya el intercambio de cartas relativo al desafío y nos detalla los sucesos del espectáculo de Granada.

La Crónica anónima de Enrique IV de Castilla. Madrid, 1991, pp. 290-293, nos da más detalles que la anterior lo que nos ayuda a complementarla, abundando en pormenores del desafio con el detalle de la circulación epistolar.

La Historia de la casa de Córdoba, de D. Fernandez de Cordoba, Abad de Rute, contenida en el Ms. 3271 de la Biblioteca Nacionai aporta una carta de Enrique IV relevando a don Diego del juramento hecho a don Alonso bajo presión.

En las Relaciones de algunos sucesos de los úttimos tiempos del Reino de Granada, escritas por Hernando de Baeza y publicado en Madrid en 1868 por la Sociedad de Bibliófilos tenemos los "Documentos relativos al desafio de D. Alonso de Aguilar y D. Diego Fernández de Córdoba", pp. 69-152. Este artículo nos aporta las cartas enviadas por don Diego a su oponente, las remitidas por el rey de Granadas a ambas partes. asi como otras realizadas por personajes secundarios en los hechos. 
camente un pequeño relato escondido entre los fondos de la Biblioteca Nacional parece haber utilizado documentación procedente de la casa de Aguilar ${ }^{5}$.

Ambas casas, que procedian de un mismo linaje ${ }^{6}$, estaban enzarzadas en una de las frecuentes guerras privadas que los poderosos acostumbraban a realizar para aumentar su parcela de poder en sus zonas de influencia. Conflicto que no era sino la expresión local de la pugna que en los revueltos "tiempos rotos" de Enrique IV sostenian éste y los nobles rebeldes que apoyaban las pretensiones de sus hermanos, primero, Alfonso y, posteriormente, Isabel ${ }^{7}$. El conde de Cabra, el obispo de Córdoba, don Pedro de Córdoba y Solier, y Martín Alfonso de Montemayor defendían la causa de Enrique IV. Por otro lado el alcaide de Los Donceles ${ }^{8}$, Luis Méndez de Sotomayor, señor de El Carpio, y don Alfonso de Aguilar a quien seguian los conversos y la gente del común apoyaban al príncipe Alfonso. Enrique IV trató de mediar entre ambas facciones, aunque su debilidad impedía la intervención directa y contundente para imponer la paz. Su mediación, sin embargo era interesada demostrando su parcialidad con el conde de Cabra al que iba colmando de honores en lógico pago de la ayuda prestada en el sostenimiento de su posición. En virtud de ello se le concedió la tenencia de Alcalá la Real, para más tarde como agradecimiento al apoyo mostrado en el sometimiento de la rebelde ciudad de Écija se le otorgó el dominio de las villas de Rute, Zambra e Iznájar, ésta con título de vizconde. Además recuperó los castillos y demás fortificaciones de Córdoba que de acuerdo con su cargo de alguacil mayor le correspondia detentar y que hasta entonces estaban en manos de su rival. Ante estas lógicas muestras de preferencia regia, Alonso de Aguilar vio el peligroso reforzamiento de la posición de la casa de Cabra en la zona que le relegaba a una posición secundaria por lo que decidió actuar contundentemente en cuanto tuviera oportunidad.

El 25 de octubre de 1469 don Diego de Córdoba fiándose de la paz que en esos momentos mantenía su padre con Alonso de Aguilar acudió a la ciudad de Córdoba sin desconfianza alguna en la invitación que éste le hizo por medio de don Alonso Arigulo para que acudiera a comer con él. Finalizado el refrigerio fue prendido, junto a su hermano don Sancho, por el comendador de la orden de Calatrava don Diego Carrillo. Esta conducta que asi a primera vista parece tan impropia

5 Está incluido en los Apuntamientos históricos de Ambrosio de MOrales, es el fragmento duodécimo intitulado: "Lo que pasó en el desafío de don Alonso de Aguilar y el conde de Cabra" (Ms. 1223 de la Biblioteca Nacional, ff. 182 v.-185 r.).

6 Don Alonso de Aguilar representa la rama primogénita del linaje mientras que la comandada por el conde de Cabra apenas tenía cuarenta y seis años de antigüedad, desde la muerte en 1424 de don Alfonso II Fernández de Córdoba. La casa de los señores de Montemayor y Alcaudete y la de los Alcaides de Los Donceles eran las otras dos ramas desgajadas del árboi principal hacia ya más de un siglo.

Un estudio más pormenorizado de los hechos que conforman esta convulsa época se pueden seguir en Historia de Andalucia llI. Andalucia del Medievo a la Modernidad (1350-1504), bajo la dirección de Manuel Gonzalez Jimenez y José Enrique LoPez de Coca Castaner. Madrid-Barcelona, 1980; y en Quintanilla Raso, M." Concepción. Nobleza y Señorios en el Reino de Cordoba. La Casa de Córdoba (siglos XIV y XV), Córdoba, 1979.

* No era posible mantener una posición neutral en tiempos tan revueltos y asi nos aparecen implicadas todas las ramas del linaje de los Fernández de Córdoba. 
de un caballero y que las crónicas se encargaron ampliamente de divulgar tenía su justificación. El caso era que don Diego había estado abasteciendo de forma subrepticia el alcázar de Córdoba de gentes, armas y municiones por lo que don Alonso vio peligrar gravemente su posición en la ciudad y decidió adelantarse a las maniobras de su rival asestando el primer golpe.

Don Diego fue trasladado prisionero a la fortaleza de Cañete de las Torres donde ignominiosamente se le encerró en una jaula de madera, mientras su hermano permanecia junto a don Alonso. Inmediatamente este tomó las puertas de la ciudad y puso sitio al alcázar y la calahorra ${ }^{9}$, únicos lugares ajenos a su autoridad. El Abad de Rute da una versión un poco diferente según la cual don Diego de Cabra al conocer la situación de sus hijos movilizó sus fuerzas para atacar Cañete. Don Alonso carente de recursos con los que sostener este castillo se trasladó junto con sus prisioneros a Córdoba, siendo aquí donde encerró ignominiosamente a su rival en la jaula ${ }^{10}$.

Privado de su libertad y presionado por su captor, Pedro de Maderero, y otros que le advirtieron cómo don Alonso se proponía utilizarles como proyectiles contra el alcázar ${ }^{11}$, don Diego de Córdoba tuvo que ceder a sus pretensiones. Se acordó la entrega de diversas posesiones, lo que otorgó por escrito y firmó junto a su padre, don Diego, cabeza de la casa de Cabra, y otros miembros relevantes de su linaje. En diciembre de ese mismo año se entregó el alcázar y la calahorra a las gentes de don Alonso ${ }^{12}$. Alcalá la Real quedó momentáneamente en manos de Juan Pacheco, maestre de Santiago, quien debía resolver la cuestión de su propiedad teniendo de plazo para ello hasta el dia de San Juan Bautista de ese mismo año. Don Sancho quedó en libertad merced a los buenos oficios del maestre y del duque de Medina Sidonia pero don Diego fue puesto en manos de don Fadrique Manrique de Écija, hermano del conde de Paredes, y de Luis de Pernia, alcaide de Osuna, villa del conde de Cabra, quienes prestaron homenaje a don Alonso comprometiéndose a su entrega si llegada la fecha antedicha no se hubiera dado solución a las cuestiones en litigio.

Lograda su libertad don Diego no perdió el tiempo en informar al rey del agravio que se habia cometido en su persona. Enrique IV se lo tomó bastante mal, ya que no en vano y fuera parte de la prisión de uno de sus aliados principales, el hecho es que se habia quebrantado la paz y amistad que él, el rey, personalmente, había puesto entre ambos linajes en la primavera de 1469 . Expidió carta ${ }^{13}$ a quin$c{ }^{14}$ de abril de 1470 que fue ampliamente publicitada en las puertas de iglesias y otros lugares de concurrencia, como plazas y mercados, por la que invalidaba to-

La Crónica anónima de Enrique $\mathrm{V}$ de Castilla se refiere a estas defensas como la fortaleza de Córdoba y la Torre de la Puente, p. 291.

D. Fernandez de Cordoba, Historia..., cit., f. $102 \mathrm{r}$.

1 R. Ramirez de Arellano, Historia..., cit., p. 248.

ibid p. 249

1.1 N. Albornoz, Historia..., cit., Apéndice 5, pp. 437-440.

${ }^{14}$ once de abril, según A. de Morales, Apuntamientos..., cit., f. 182r. 
dos los acuerdos a que habian llegado ambas partes durante la estancia de don Diego en prisión. Además se requeria a este último a que se personara en la corte, dándole quince dias de plazo tras su recepción.

Totalmente libre ahora don Diego, pues hasta entonces sólo lo era de su persona ya que su voluntad estaba limitada por su juramento y su firma, decidió arreglar particularmente la afrenta. Es así, que sin esperar la solución que el rey debía dar tras la finalización del plazo para la personación de don Alonso decidió recurrir a las armas.

El 27 de mayo don Diego remite carta ${ }^{15}$ al rey por la que solicita su autorización para reptar a don Alonso por alevoso por que:

(...) me prendio con la dicha su gente armada; lo qual hizo sin preceder desafío, que por el me fuese fecho, ni injuria que yo le hiciese, ni otro caso por donde me deviese prender, como me prendió; y en la prisión que me hizo, me trató asaz injuriosamente, por lo cual según las leyes y premáticas reales de vuestros reynos, el dicho don Alonso incurrió en crimen e caso de aleve.

Desea afearle su conducta ante él y con la ayuda de Dios, la Virgen y el apóstol Santiago hacerle confesar su equivocación o en su defecto echarle del campo o matarle ${ }^{16}$. En los dos primeros casos quedaría demostrada la culpabilidad de don Alonso, con lo que estaba ya expuesto a la justicia real para que le impusiera las penas establecidas en el ordenamiento vigente. La tercera pretensión de don Diego, la muerte de su rival, es un objetivo menor puesto que el hidalgo que muere en la lid anexa a un riepto regio no es considerado culpable ya que ha defendido su postura y, por lo tanto, su honor permanece incólume ante todos los demás ${ }^{17}$. El reptador no logra su objetivo principal que es lograr la completa desacreditación de su adversario y ello sólo se logra con su calificación como alevoso o, en su caso, traidor.

Como vemos la intención de don Diego es la de entablar a toda costa combate con don Alonso. No muestra ninguna predisposición a aportar otros medios de prueba que no serian difíciles de presentar ya que los hechos eran de notorio conocimiento público. Asi se pone en conocimiento de Enrique IV que en el supuesto que no se acepte su petición, expresa o tácitamente, será él mismo quien tutele su honra y trate de lograr satisfacción adecuada buscando lugar y manera al

15 D. Enhiquez del Castillo, Crónica..., cit., p. 266

1 Fuero Real 4,21,6: «Quiquier que a otro reptar quisiere, déuel reptar en esta guisa: fágalo lamar antel rey e depués que fuere delantel rey diga el fecho por que riepta e digal que es ende aleuoso e que ge lo fará dezir ol matará ol porná fuera del pleyto; et si ge lo quisiere prouar por iestigos o por carta o por pesquisa del rey, digágelo et el reptado diga que miente; e sił quisiere combater, digágelo; et si non quisiere combater, diga que fará quanto el rey mandare».

1) Fuero Real 4,21,10: “Si el reptador fuere muerto en el cámpo, el reptado finque quito del riepto, maguer que el reptador non se aya desdicho; et si el reptado muriere en el campo e non se otorgue por aleuoso o non otorgare que fizo el fecho de que fue reptado, muerra quito del riepto, ca razón es que sea quito qui defendiendo su uerdat prende muerte". De manera muy semejante también se encuentra recogida esta materia en Partidas $7,4,4$. 
efecto. Todo ello sin incurrir en ninguna pena al haber quedado desprotegido. Bien claro tenía que el rey le denegaria su petición y acabaria por limitarse a manifestar su malestar a don Alonso por su actuación impropia pero sin llegar a mayores. Sabe además que por las leyes existentes tampoco puede recurrir al duelo privado por lo que notifica al rey que buscará un príncipe más condescendiente con su situación. La impresión que da la carta es la de una mera excusa para justificar su posterior petición de duelo a don Alonso.

A partir de este momento la cuestión deviene enteramente privada y comienza el típico intercambio de cartas entre los duelistas y que desembocará en sendas escenificaciones teatrales. Apenas van a transcurrir ochenta y seis días entre el envio el 24 de junio de la primera carta hasta el 17 de septiembre en que tiene lugar la actuación de don Alonso. No llega a los tres meses el desarrollo de todo un proceso, mientras que en otros sucesos similares, más caballerescos y menos politicos, como el protagonizado por Joanot Martorell y Joan de Monpalau un simple trámite como el de la elección del juez tenía pactado un plazo de seis meses, y todo el tráfico de cartas se extendió durante veintitrés meses sin llegar a culminarse, real o ficticiamente ${ }^{18}$. La proximidad entre los territorios de los nobles castellanos ayudó, eso sí, a la rapidez con que se produjo el intercambio epistolar.

El prólogo de nuestro relato tiene fecha 23 de junio, data de la carta por la que don Alonso siguiendo los acuerdos alcanzados meses antes demanda a don Fadrique y a don Luis la entrega del Mariscal. Estos lógicamente no pueden cumplirlo ya que a don Diego ni se le había ocurrido entregarse a ellos para acabar en manos de su rival, y claro es, que también el de Aguilar lo sabía, pero es preciso que cada parte siga el papel que le corresponde si quiere aparecer como justa y descargar todo el oprobio sobre su oponente.

El 24 de junio ya se inicia la correspondencia entre nuestros dos actores principales con el primer requerimiento ${ }^{19}$ de don Diego a su rival. La carta es breve y su estructura es la típica de estas ocasiones: relación de los hechos, acusación de la conducta dolosa, requerimiento para que cumpla su parte en los preparativos del combate, amenazas varias si no cumple con el papel que le toca, opción de duelo privado sin tanta ceremonia y propuesta de rehenes. Las siguientes cartas no se mostrarán tan precisas y a la par que incrementan su extensión se desvian a asuntos accesorios, aparecen los insultos, surgen hechos pasados que incluso atañen a familiares ya desaparecidos. Cuando ya se cansan de estas dilaciones se dan un baño de moderación y dicen callar otros hechos que serian en demérito de su rival pero el conflicto no avanza pues ahora ya no se ponen de acuerdo en diversos pormenores: unas veces las armas que no contentan a alguna de las partes, otras es el campo que no parece seguro, cuando no son los rehenes que no alcanzan un mismo nivel.

1 Vid. M. de Riouer y M. VARgas Llosa, El combate imaginario: Las cartas de batalla de Joanot Martorell, Barcelona, 1990

${ }^{19}$ H. de Baeza, Relaciones..., cit, carta 1, pp. 71-73. 
La carta es muy reveladora de la consideración que se daba en Castilla del duelo como método de resolución de conflictos privados. En primer lugar se produce una incorporación de elementos legales en un asunto privado como es la calificación de aleve para la conducta de don Alonso. Mezcla que es típica de estos momentos finales del Medievo y que culminará en el siglo XVI con la eliminación de cualquier referente jurídico:

(...) la infamia y manzilla de aleue, en que según las leyes destos Reynos cahe qualquier onbre fijo dalgo que a otro fijo dalgo mata, o fiere, o prende, sin le aver primero desafiado y le aver tornado el amistad que antiguamente fue puesta entre los fijos dalgo despaña, tratándome vos amigablemente, como pariente, et habiéndome conuidado, et salua fe, quebrantado la dicha amistad, (...)

Continúa luego requiriéndose al desafiado para que señale las armas y el modo de lucha, a pie o a caballo, con el que se realizará el combate mientras que él se compromete a encontrar persona principal, rey o príncipe, que les garantice campo seguro.

Si no le place un duelo revestido de tanta formalidad siempre cabe la posibilidad de venir antes a las manos y prescindiendo de todo el proceso habitual dilucidarlo rápidamente. Propone que en zona neutral, entre Aguilar y Cabra o entre Alcalá y Priego, se personen ambos acompañados de un faraute que actúen como testigos de su actuación. Con este ofrecimiento nos encontramos que se han propuesto tres tipos diferentes del duelo por parte de don Diego, cada uno de los cuales aparece revestido de un grado inferior de solemnidad y garantías respecto de su precedente. En primer lugar se produjo el riepto ante el rey, éste es un procedimiento jurídico que de haberse llevado a cabo estaría rodeado del más elaborado ceremonial y de plenas garantias, no en vano es el rey quien se hace cargo de todos sus pormenores. En segundo lugar, se ha visto un duelo privado, tutelado por un personaje principal, procedimiento extrajurídico cuya parafernalia y seguridad son inferiores al anterior pero muy superiores al siguiente. El último se trata de una simple riña privada, cuya única seguridad es la presencia de padrinos de ambas partes; pero si consideramos que estos individuos son personas vinculadas a los contendientes no podríamos asegurar que ellos mismos se implicaran en los hechos supuesto el caso de que su señor se viera en situación apurada $^{20}$.

Termina ofreciendo como rehén a su hijo primogénito quien será puesto a cargo de un caballero elegido por don Alonso, y sugiere que el hermano de éste, Gonzalo Fernández, el futuro "Gran Capitán", quede junto al caballero que diga

20 En todo caso se nos muestran más formales que otros personajes como Pedro de Torrellas y Jerónimo de Ansa, quienes años más tarde, en 1522, y por un asunto irrelevante, una discusión en el juego de pelota, acordaron una simple pelea sin testigos, a pie y con tan escaso armamento como espadas. En esta sucesión se ve ia pendiente por el que rueda la pugna duorum como instrumento para resolver disputas entre nobles, desde el supremo recurso al riepto por causas graves y objetivas a la riña nocturna por un lance insignificante. 
don Diego. No obstante queda abierta la posibilidad de acordar cualquier otro tipo de seguridad que convenga a ambos.

Entretanto don Diego se mueve con rapidez y simultáneamente escribe al monarca nazari solicitándole que actúe como juez y prepare el campo. Este inmediatamente le contesta aceptando su papel y remite a ambos implicados sendas cartas de seguro el día 1 de julio. En estas cartas Abu-I-Hasan se compromete a juzgar "el fecho con la verdad et justicia et la costumbre", recuerda a don Alonso el derecho que tiene de escoger armas a pie o a caballo, y les cita el 10 de agosto siguiente para la celebración del combate. Su misión ha concluido hasta ese día, mientras tanto ellos sólo deben de preocuparse «la manera que entre vos et él será concertada de las armas".

Es de notar la situación de amistad entre la casa de Cabra y el rey de Granada, aunque más adelante se dirá lo contrario, y que se observa en la carta de aceptación ${ }^{21}$ donde don Diego aparece tratado como "caballero noble, ilustre, distinguido, estimado, esclarecido, cumplido» para unas líneas más adelantado manifestar que «accedimos á vuestra petición, por honraros á vos y á vuestro padre, nuestro amigo, el caballero noble, distinguido, renombrado, cumplido"; por otro lado don Alonso de Aguilar es simplemente "caballero don Alfonso de Aguilar». Más contundente es aún el final de la carta: «para que vengáis a esta nuestra capital al desafío, como habéis dicho y pedido, pues vos sois de nuestros más sinceros y distinguidos amigos. Todo por deferencia a vos y a vuestro padre. Dios os conceda su favor".

En el documento espedido por el rey de Granada tras la no presentación de don Alonso de Aguilar, don Diego era el "cauallero honrrado et el esforzado, et fidalgo et conplido, el descogido et el nonbrado et el enzalzado et el cortés et conplido en todas las cosas" y su oponente el "cauallero don Alfonso, señor de Aguilar» pero es que más adelante el mismo rey de Granada dice claramente: «Et juro por Dios que en nuestro corazon no estaua de le facer mal ni aleuosya ni traycion, et no teniamos pensado sy no de le facer toda honrra et todos los bienes et cosas que le pudieramos facer».

La armonía existente entre la casa de Cabra y el rey nazari se constata en la cuantía de los numerosos regalos que ofreció tanto a éste como a varios de sus súbditos principales y que ascendieron a la cantidad de 153.312 maravedis ${ }^{22}$ (192.912 según Ramírez de Arellano). Lo normal es que cuando un caballero solicita campo seguro para un duelo privado o al pedir autorización para la realización de una empresa sea el soberano quien incurra en todos los gastos. Acontecimientos como estos dan lustre a su ciudad y gustosamente aceptan el dispendio, que se ve incrementado con los regalos con que despiden a los participantes. Así ocurrió en 1411 en esta misma ciudad de Granada con motivo del combate entre

\footnotetext{
21 H. DE BAEZA, Relaciones..., cit., carta III, pp. 80-83.

$x^{2}$ ibid, carta XI, pp. 115-119.
} 
Juan Rodriguez Castañeda, señor de Fuentedueña, e Íñigo de Estúñiga quedando en el recuerdo del cronista la honorable actuación de su predecesor Yusuf III al-Nasir ibn Yusuf quien: "honrólos quanto pudo, é dióles sus dádivas como en tal caso se acostumbran, é hízolos amigos, y embiólos en Castilla» ${ }^{23}$. Las crónicas castellanas de este siglo muestran otras numerosas ocasiones en las que se menciona la entrega de regalos - ropas ornadas de marta cibelina, caballos, vajillas de plata o joyas - a aquellos caballeros que acuden a Castilla a sostener una empresa o a los castellanos que se aventuran por Europa en sus lances caballerescos.

La amistad de Abu-I-Hasan con la casa de Cabra se manifestó también pocos años después cuando el conde de Cabra intermedió en la firma de una tregua entre los Reyes Católicos y el monarca granadino.

La corte de Granada ya había sido utilizada, en 1447 por Gómez de Figueroa y el valenciano Bernat de Vilarig. En este lance Vilarig fue asaltado y malherido en su viaje a la corte granadina en las cercanias de Totana a lo que parece con la complicidad de Alonso Fajardo, personaje principal en el reino de Murcia y muy cercano a Figueroa. Cuando remitió hasta Granada a su rey de armas, Valencia, con una carta detallando la imposibilidad manifiesta de presentarse en la fecha del combate no fue siquiera recibido por el rey de Granada siendo oficiales suyos quienes desatendieron las justas razones expuestas y permitieron a Figueroa la representación del ritual que simbolizaba la derrota y la ignominia de Vilarig ${ }^{24}$. En este punto nos planteamos una pregunta: ¿acaso eran conocidos por Alonso de Aguilar estos pormenores y previó una encerrona similar?

Otro recurso hubiera sido acudir ante el rey de Navarra o el de Aragón quienes ya habian sido requeridos como jueces en conflictos entre castellanos y naturales de sus reinos sin que en ningún caso hubiera suspicacias por su intervención. De haberse desarrollado los hechos unos años antes siempre hubiera quedado el recurso de don Pedro de Meneses, gobernador portugués de Ceuta, como asi hicieron Lope Alfonso de Montemolín y el valenciano Felip Boyl, y en 1433 los también valencianos Joan y Pere Fabla que quisieron medir sus fuerzas con Suero de Quiñones y Lope de Estúñiga.

El caso es que como castellanos no podian combatir en el interior del reino donde no se permitía siquiera los desafíos caballerescos existiendo legislación al respecto como la emitida en Tudela en 1409. De hecho el mismo Juan II se dirigió a Pedro de Meneses para que diera campo a Montemolín y Boyl ${ }^{25}$. Si tenemos referencias de combates más generales como torneos, justas, empresas y pasos pero aqui su autorización sólo tiene dos razones la utilización política del espectáculo o la cortesía hacía caballeros extranjeros. Si hiciéramos una comprobación

3 F. Pérez de Guzmán, Crónica de Juan II, BAE 68, Madrid, 1953, p. 373

24 M. de RIQuER, "El caballero Bernat de Vilarig" en Caballeros medievales y sus armas, Madrid, 1999, pp. 79-102.

${ }_{25}$ M. de Riquer, Caballeros andantes españoles, 126. 
de cuántos duelos de este tipo se hicieron en Castilla sólo encontramos un ejemplo en tiempos de los Reyes Católicos y otro, ya más tardio, en época de Carlos I, pero en ambas ocasiones los implicados eran naturales de la corona aragonesa ${ }^{26}$.

Responde el 3 de julio don Alonso por medio de su rey de armas, Sidonia, que en el momento de los hechos no existía seguridad dada entre ellos, sino enemistad, pues con anterioridad el Mariscal y su hermano, Martín Alfonso, salieron al vado seco de Guadajoz entre Bujalance y Montilla y le enviaron dos trompetas para desafiarle. Batalla que fue aceptada aunque contaba con menos gente ${ }^{27}$ pero que no recibió respuesta a su aprobación con lo que desde entonces entiende que estaban enemistados y que su proceder en Córdoba fue justo. Abundando en el tema entiende que aún el posterior riepto que le hizo era improcedente pues tenia empeñada su palabra tras su prisión.

Turno ahora para don Diego, quien el 7 de julio remite una carta muy exten$\mathrm{sa}^{28}$, en la que acusa recibo de la anterior misiva de su rival. Este escrito muestra las caracteristicas típicas de las cartas secundarias con prolijidad de tópicos como el recurso inmediato a descalificar y desprestigiar su respuesta. Se le tacha así de cobarde: "paresce cuanto vos plaze fuyr la batalla que venyr en conclusyon de aquella, dando vuestras vergonçosas dilaciones et injustas excusas, muy ajenas de los animosos et nobles caualleros" y "satisfaciendo vuestra no verdadera et mugeril respuesta». Se le afea el recurrir a sucesos ya pasados que no tienen que ver con la actual coyuntura y que además no sucedieron como él lo afirma sino de muy distinta manera. Así a lo que sostiene acaecido en el vado manifiesta que se le requirió se apartara para que ellos pasaran a su lado a combatir o bien, a la inversa, ellos se alejarian para que él pasara y comenzara la lucha. Más aún, su hermano y él le habían propuesto que se acercara a la mitad del vado junto al alcalde de Los Donceles y así los cuatro dirimirian la cuestión sin que sufrieran daño sus hombres; lo cual se hizo porque estaban al servicio del rey.

Afirma don Diego que existen cartas firmadas por él, don Alonso, en las que se muestra la situación de amistad y transcribe las mismas en apoyo de su postura. Aparte de todo ello están las muestras públicas de reconciliación, el abrazo ofrecido por don Alonso y aceptado por él en la iglesia de San Francisco, que ambas partes demostraron con motivo de la visita del rey a Córdoba el dia del Corpus. La primera de estas cartas se habia realizado tiempo después de los sucesos del

26 En 1476 combatieron en Sevilla los catalanes Juan Perez Seminate y Luis Margarit ante Fernando el Católico. En 1522 hicieron to propio en Valladolid ante Carlos I los aragoneses Pedro de Torrellas y Jerónimo de Ansa.

27 Este es un lugar común al que se recurre siempre en estos casos alegando la valentía de aceptar un combate aún contando con menos gente, se trata con ello de ir poco a poco inclinando la opinión pública a su favor. En otras ocasiones, en los duelos bélicos que se producen en esta época es común un recurso semejante y asi cuando dos ejércitos se encuentran frente a frente, los principales de cada parte deciden combatir entre ellos. Aqui encontramos que siempre uno de éstos alega que aún contando con fuerzas superiores prefiere arriesgar su persona al peligro a fin de evitar el derramamiento de sangre que se produciria caso de librarse un combate general.

28 H. DE Baeza, Relaciones..., cil., carta II, pp. 73-80. 
vado y la segunda fue apenas tres días antes del prendimiento. Abundando en lo mismo, le recuerda como el dia del prendimiento él se personó en la residencia de Egas de los Ríos, su tío, y en presencia de él y del señor Portocarrero fue abrazado muy amigablemente e invitado a comer.

Rebate también la acusación que le habian hecho de haber abastecido secretamente el alcázar de Córdoba, puesto que, muy al contrario, había sacado gente de alli cuando poco antes tuvo que dirigirse a Palma. Sostiene que el riepto fue correcto pues la seguridad estaba dada hasta el día de San Juan y éste ya había pasado, y que lo podía haber hecho con anterioridad pues su comportamiento había dado suficientes muestras de haber roto el acuerdo. Respecto a todo lo dado en Córdoba durante su prisión no lo acepta pues lo hizo acuciado por la situación en que se hallaba, con temor de su vida y la de su hermano, don Sancho, y que existen personas de crédito, como don fray Pedro Maderero, que así lo pueden atestiguar. Por ello no debe cumplir nada de aquello ni de la fe y homenaje comprometido con don Fadrique y Luis de Pernia, tanto más quanto que el rey le libró de su cumplimiento.

Le echa en cara las excusas dadas para el combate amparándose en el ordenamiento legal que limitaba este hecho entre nobles e hidalgos ya que lo único que demuestran eran las pocas ganas que tenía de arriesgar su vida. Le reitera su derecho de divisar las armas que él por su parte ya ha encontrado quien les dé campo seguro, en la persona del rey de Granada, Abu-I-Hasan, y en prueba de ello le remite copia del seguro dado por este rey donde les emplaza el 10 de agosto para la lucha. Vuelve sobre la posibilidad del combate informal en las condiciones ya reseñadas en la primera carta en los lugares antedichos o en otro cualquiera que le convenga a mitad de camino desde Baena a Cabra ${ }^{29}$.

Mientras tanto se constata como aparece una correspondencia secundaria motivada por los carteles de desafío que los fiadores de don Diego van a enviar a éste. Vienen obligados para guardar las formas, ya que de no comportarse asi parecerian tomar parte por don Diego puesto que no lo tienen en su poder y además no actúan contra él. Don Fadrique le desafía, sin fecha precisa, por alevoso y se ofrece a combatirle a muerte enviándole un cartel con los pormenores del combate. Conservamos una carta del 16 de julio por la cual don Diego rechaza un segundo cartel enviado por Luis de Pernia porque "no conviene por agora otra nueva respuesta, fasta que plega a Dios que yo venga en conclusión de las armas que tengo emprendidas con el alevoso don Alfonso d'Aguilar ${ }^{30}$ ". Entretanto recibe la ayuda de su hermano, don Martín, comendador de Estepona, quien estaba enfadado con don Fadrique, al haberle quitado este, años atrás, la gobernación de Écija. No consta que don Fadrique llegará a las manos con ninguno de los dos hermanos ni tampoco que se produjera intento alguno de continuar el proceso.

${ }^{29}$ El recurso de señalar el campo en el punto medio del camino que separa sus dominios o justo en la divisoria de los mismo cuando son aledaños se atestigua incluso en el duelo de Carlos l y Francisco I. El César propuso como lugar de celebración del duelo el rio Bidasoa, bien en una isla, en un puente o en una galera varada en medio del mismo.

${ }_{30}$ H. DE BAEZA, Relaciones..., cit., carta VI, p. 90. 
Por su parte, don Alonso se toma un tiempo pues hasta el 27 de julio no se decide a responder ${ }^{31}$, éste es un lapso de tiempo considerable para lo que se estila en el resto de las cartas usualmente respondidas en apenas dos días. Desmiente cuantas acusaciones le hace don Diego y pasa al ataque echándole en cara que aprovechando la situación delicada en la que se encontraba el rey, él y su padre se apropiaron de diversas rentas que le pertenecian y le demandaron la tenencia de Alcalá la Real bajo amenaza de pasarse al bando nobiliario. Acaba por aceptar el duelo estrictamente privado entre Cabra y Aguilar. Sugiere que vayan acompañados de dos caballeros desarmados que atalayen el camino; los del Mariscal lo harán hacia Cabra y los suyos hacia Aguilar. La fecha para este encuentro es el 15 de agosto y en fechas posteriores le remitirá carta en la que designará las armas.

El 29 de julio recibió el Mariscal esta carta ${ }^{32}$ y ese mismo día expidió su respuesta. No se queda corto en la calificación que le otorga: "alevoso y mentiroso, mengua y flaqueza de coraçon, como buscays cabtelosas dilaciones". Se le echan en cara los muchos bienes recibidos del conde de Cabra y se hace mención de un escrito, de contenido desconocido, refrendado por don Diego y su padre, que se había dado a ruegos de la propia madre de don Alonso «la qual la demandó temiendo vuestra maluada condición et desmesurada cobdiçia". Niega las acusaciones que se le hacian de chantajear al rey, y le acusa de hechos semejantes como la usurpación de la ciudad de Córdoba y la retención de las rentas debidas al rey, asi como otras exacciones indebidas "enprésydos et sysas et otros esquesytos modos de roberias". Pone fin a este cruce de acusaciones no por que no pudiera afearle su conducta en otras ocasiones "dexando de dezir otras cosas que con mucha verdad dezir podria" sino "por no gastar el tiempo en palabras", deja zanjado así este apartado de mutuas acusaciones que no vienen al caso no sin antes verter algunos insultos; "tomando el oficio de mujer que vos seguis", "mas ya paresce que soys de Sant Lázaro». Respecto al asunto de las treguas alega tener cartas firmadas por él y entregadas por Gonzalo de Cáliz y Gonzalo de Cárdenas, por la que se le daba tregua apenas tres dias antes de ser prendido. Se muestra muy ofendido ante la negativa a aceptar al rey de Granada como juez del combate y le intima a aceptarlo como obligación que tiene: "et digo que deueys ir antel señor rey de Granada don Abulhaçen al tiempo por él a vos asignado, asy porque de derecho de armas sois tenido de me seguir donde vos yo llamare, como por aver rrescebido el seguro suyo". No le valen las reticencias que muestra don Alonso de acudir ante el rey nazari por "le haver quemado y estragado su tierra" pues él y su familia han obrado en otras ocasiones mucho más valientemente contra Granada y que debian ser ellos quiénes deberían estar más recelosos con Abu-I-Hasan. A continuación pasa a relatarle de forma minuciosa los altercados antedichos, lo que ocupa una tercera parte de la carta, de este modo y sin tener que recurrir a acusaciones o insultos eleva su persona por encima de la su oponente.

A. de Morales, Apuntamientos..., cit., f. 183 r.

H. DE BAEZA, Relaciones..., cit., carta VII, pp. 91-97 
Llegando al final de la carta se centra por fin en cuestiones relativas al combate, aceptando el quince de agosto como fecha del mismo, no sin antes recordarle que se ha saltado el protocolo ya que el retado debe "deuisar las armas treynta dias antes de venyr al trançe, ó á lo menos veynte» ya que su última carta era de 27 de julio y no se hacia referencia alguna a las armas. También le acusa de ignorarle su petición de duelo privado ya que él sólo admitía la presencia de un faraute y le intima el pronto intercambio de rehenes en las personas de su hijo que pasaría a ser custodiado por el caballero que él quisiera y en la de su hermano Gonçalo Fernández, que quedaría junto a su hermano don Gonçalo. Le requiere que prontamente, exactamente cuatro días, le responda la carta, indicando las armas y nombrando el caballero que se hará cargo de su hijo.

La urgencia que le transfiere en su carta don Diego parece que hace efecto en don Alonso pues el 3 de agosto emite su respuesta ${ }^{33}$. Tras el consabido insulto, "mentiroso", encabezamiento común de todas las cartas, pasa a señalar las armas: "capacetes fojas e faldas e quixotes con sus banesas, escudos, guardas derechas e sendos manteles derechos, adargas de ante espadas e puñales que cada uno aya quince palmos, caballos de la gineta con sillas jinetes". Ahora bien no encuentra igualdad en los rehenes pues su hermano Gonzalo es el único heredero de su casa mientras que existen varios en la suya, el mismo don Diego, sus hermanos y los hijos de éstos, por lo que propone a su vez que sean su padre, el conde de Cabra, o su hermano don Martín. Exige que los rehenes pedidos sean puestos en manos de Pedro de Angulo, y que el uno o el otro dé una fortaleza en que los tenga. Termina apremiando se terminen las cartas no sin antes señalarle que si el combate tiene efecto es por su voluntad ya que siendo su persona y estado muy superior a la de don Diego no tiene obligación ninguna de responderle ${ }^{34}$.

A 5 de agosto don Diego expide nueva carta ${ }^{35}$ iniciada de nuevo con una andanada de insultos: "Continuando vuestra acostumbrada femenil manera que en toda cosa tenés, alevoso y malvado caballero...» que continúa poco más adelante: "aleuoso et mal cauallero, vuestras cobardes et viles cautelas, vuestro baxo e vil coraçon,...». No hay concreción alguna de hechos relacionados con el asunto o con otros roces actuales o pasados entre los participantes o sus familias:

(...) y ese mesmo linaje me costriñe callar tales cosas de vos, que puesto que á todos sean notorias, á mi serie vergonçoso dezyrlas, y á lo que tocays de la cobdiçia del conde mi señor, syn dubda es mas conoçida su franqueza que lo que maliçiosamente dezys de que muchos testigos ay en Castilla, et algunos en vuestra casa, et fartos en esa çibdad; dezys más algunas cosas que pasaron entre el conde mi señor y el señor don Pedro de Aguilar, que Dios aya á las quales ceso de rresponder, porque sy entre ellos algunos debates pasaron, ellos fueron tan virtuosos, et asy buenos caualleros, que nunca cosa fea por ellos se cometió, avnque cada

33 A. de Morales, Apuntamientos..., cit., f. 183 r-v.

${ }_{34}$ Aqui está equivocado don Alonso, la diferencia social sólo se puede alegar en los supuestos de rieptos y su disputa ya es puramente caballeresca.

${ }_{35}$ H. DE BAEZA, Relaciones..., cit., carta VIII, pp. 98-102. 
uno de ellos muchas veces del otro se confió; pues dexad de fablar de los pasados et del conde mi señor en quien ningun rreproche se puede poner, et dexando de vos rresponder particualrmente a cada una de las otras canas et locas et desonestas cosas que por vuestro cartel dezys, por non ser mal diziente como vos, digo que todo lo por mi á vos en mis carteles escrito es verdad, y en todo quanto aveis dicho y dezys aveys falsamente mentido, et mentis et mentirés quando quiera que sostenerlo querrés (...)

Rechaza don Diego la nueva propuesta sobre rehenes hecha por su rival, la figura del conde de Cabra está fuera de toda pretensión mientras que el gaje de batalla en el que a su vez se encuentra metido don Martín con don Fadrique Manrique impide también que pueda convertirse en rehén. Propone dos nuevos rehenes, sus hermanos Sancho y Gonzalo, y un caballero neutral, Pedro de Angulo, tío de ambos contendientes, para que custodie a los rehenes. Reitera que vayan a Granada o, a lo menos, a terreno neutral entre Cabra y Aguilar:

Que venga ese día a la lucha para que con la ayuda de Dios et de nuestra señora et del byenaventurado apostol Santiago et de mi verdadera et justa querella y con la sola presencia de Çeli, haraute, y Sidonia, rey de armas. Que hay que combatir ya que cosa vergonçosa es entre caualieros gastar tanta tinta et papel sin venir á las manos.

El 10 de agosto don Alonso agradece a Pedro de Angulo su disposición a custodiar a los rehenes de ambas partes ya que el Mariscal no ha aceptado la propuesta que sobre ellos le había hecho por lo «que yo me vo a la mi villa de Aguilar, segund por él fue ya dicho, y él venido a la villa de Cabra alli se dará a él plaziendo otra seguridad, que a mi et a él igual sea, para venir al canpo por él asignado et por mí acebtado". El motivo de la carta parece estar en el desaire sufrido por Pedro de Angulo quien fue a recibir el castillo de Doña Mencía para tener los rehenes. Allí su alcaide, Pedro de Pineda, le entregó las llaves y salió al exterior, pero cuando Pedro de Angulo pidió al Mariscal que mandase salir al resto de la gente para poner él sus hombres; éste le respondió que esta situación no estaba contemplada en los capitulos por lo que no pudo tomar posesión del castillo ${ }^{36}$. Conforme a esto, el 11 de agosto ${ }^{37}$ don Alonso vuelve a escribir al Mariscal y, tras el desmentido a las habituales acusaciones de su rival, le pide envie un caballero con su faraute para que junto a uno de sus caballeros y su rey de armas señalen el campo ${ }^{38}$. Nos surge una duda ahora, ¿estaba al tanto don Alonso de los hechos acaecidos el día anterior?

Sin haberse llegado a ningún acuerdo en el tema de los rehenes llegó el día 10 de agosto en que se cumplia el plazo dado por el rey nazarí. Y allí, en Granada, cumpliendo su aviso de la última carta se encontraba presente don Diego con las armas elegidas por su oponente esperando su llegada. Tras su aparición en el

36 A. de Morales, Apuntamientos..., cit., ff. 185r.

3711 de agosto según A. de Morales, íbid., f. $183 \mathrm{v}$.

38 ibid., ff. 183v. 
campo buscó a su adversario, suponemos que dio una vuelta ceremonial por el recinto haciendo gala de su presencia, para a continuación esperarle hasta la puesta del sol. Don Diego al no presentarse su rival comenzó el ritual al uso para manifestar la deshonra en la que había caído don Alonso. Ató a la cola de su caballo, cabeza abajo, un retrato de don Alonso, y se paseó por el campo mientras gritaba: "Aqueste es el alevoso Don Alonso de Aguilar, que denegando su palabra, no vino al plazo señalado". Para mayor humillación de su rival mandó realizar varios retratos semejantes con el título: “Este es el alevoso de D. Alonso de Aguilar» los cuales fueron enviados a las principales ciudades del reino para ser exhibidos de la misma forma.

Conclusión de todo ello fue la emisión de una carta ${ }^{39}$ donde se certificaban los hechos acaecidos, quedando don Alonso en ella en muy mal lugar, aprovechando de paso el rey de Granada para mandar un recado a su homólogo castellano, eso sí guardando las debidas formas, al manifestar que:

(...) por esta nuestra carta vos declaramos et decimos que don Alfonso d'Aguilar no guardó su honrra ni estado, et no cumplió cosa de lo que era obligado, et que es cauallero aleuoso et conoscido, et no deue nadie tomar del fe ni seguro. $Y$ es mengua, fablando con rreverencia del rrey, que de tal cauallero fía capitania de gente ni gouernacion de cibdades ni villas ni lugares, como de onbre no verdadero ni conplido.

Cuando parece que ya está todo terminado, el 13 de agosto el Mariscal recibe una carta de don Alonso intimándole a combatir con seguridad de atalayas a lo que responde ${ }^{40}$ rechazando esta peculiar propuesta de combatir ya que ese modo de seguridad ha tenido lugar entre principes y grandes señores pero no entre caballeros con antecedentes tan reprobables como los suyos. Le comenta su viaje a Granada entendiendo correctos todos los sucesos acaecidos al no existir desaprobación expresa de don Alonso. No obstante quiere mostrar que no tiene inconveniente en sostener el duelo privado y para ello presenta dos ofertas de rehenes: su hermano don Gonzalo y su hijo mayor a cambio de su hermano Gonzalo Fernández quedando todos ellos en manos de Pedro de Angulo, o bien que Gonzalo Fernández permanezca en poder del conde de Cabra mientras su hijo mayor lo hará en manos del caballero que quiera don Alonso. Si se acepta cualquiera de las propuestas enviará un caballero con su faraute Çeli para elegir el campo.

Para embrollar aún más la situación, este mismo día el rey de Granada envió nuevamente, desconocemos las razones, cartas de seguro a ambos personajes para que acudieran el primer día de septiembre ante él ${ }^{41}$.

39 H. DE BAEZA, Relaciones..., cit., carta XI, pp. 111-115. Albornoz dice que el conde de Cabra a su regreso de Granada repartió 1.000 ejemplares de esta. Tamaño número nos indica la intención de divulgar con la máxima amplitud el descrédito de don Alonso. Por otro lado, una cantidad tan excesiva para ser realizada a mano, señala el uso de algún medio mecánico para su realización posiblemente planchas de madera ya que la imprenta no la tenemos probada en estos momentos en Castilla.

40 ibid., Carta XIV, pp. 121-124.

41 ibid., Carta XIX, pp. 135-136. 
El día 15 de agosto, responde don Alonso, con más premura de la habitual, que el día 17 estará en el campo que los anteriores hubieren señalado ${ }^{42}$. Quizás se da cuenta del efecto propagandístico que en su contra puede tener la representación granadina, es posible que ya comenzaran a circular los libelos en su contra por toda la zona y necesita agilizar los trámites para invertir la situación.

Ese mismo día recibe y contesta el Mariscal reiterándose en las dos propuestas anteriores añadiendo otra nueva como es la entrega de los rehenes mencionados pero en vez de quedar en manos de Pedro de Angulo lo hagan en las de sus tíos mutuos, Diego Gutiérrez de los Ríos y Egas Sancho, ofreciendo su fortaleza de Doña Mencía abastecida a placer de los guardadores ${ }^{43}$.

Don Alonso continúa con sus prisas, ya ni siquiera se molesta en escribir un cartel, remitiendo el 16 de agosto a Sidonia a la villa de Cabra para que requiera al Mariscal su presencia en la plaza señalada entre Cabra y Aguilar, amenazándole que ante su ausencia actuará conforme a la defensa de su honor ${ }^{44}$. Don Diego le responde ese mismo día a hora de vísperas, que está dispuesto a ir, al lugar señalado, siempre que se entreguen los rehenes en la forma señalada en el primer cartel $^{45}$. La respuesta es llevada ese mismo día por numerosos caballeros del Mariscal que dirigidos por Martín de Rojas, limosnero del rey, se llegaron hasta la villa de Aguilar requiriendo a don Alonso la entrega de su hermano en cualquiera de las tres propuestas ya tratadas y que hecho esto dará un caballero y un faraute que con Sidonia señalarán el campo y que si no lo hace procederá con los hechos acostumbrados en defensa de su honra. Don Alonso responde que no den testimonio del requerimiento $\sin$ su respuesta ${ }^{46}$.

El viernes 17 don Alonso procedió a contrarrestar la deshonra que se le atribuía en Granada con una representación acorde a sus intereses. En primer lugar se hizo acompañar de los escribanos reales de Córdoba para que dieran fe de los hechos y junto a ellos partió de Aguilar, desde la iglesia de Santa María la Coronada, a caballo y armado a la gineta. Iban con él fray Luis de Godoy, mayordomo mayor del maestre de Calatrava y conde de Almodóvar del Campo y Villarrubia, por padrino y Diego de los Ríos «el Mozo» a la brida. El campo designado por Sidonia era un barbecho llamado «Prado Quemado» situado a legua y media de Cabra encontrándose ya limitado y señalado con una longitud de un tiro de ballesta. Se hizo un gran ceremonial con trompetas y atabales, el rey de armas, Sidonia, llamó a ambos contendientes por cuatro veces, una en cada una de las esquinas: «Don Diego, Mariscal de Castilla venid al campo limitado por vuestros carteles a cumplido pedido por el muy magnífico y virtuoso señor don Alonso de Aguilar, señor de la casa de Aguilar". Don Alonso mientras tanto buscaba a su oponente, esto es cabalgaba de

42 A. de Morales, Apuntamientos..., cit., ff. $183 \mathrm{v}$.

43 H. DE BAEZA, Relaciones..., cit., Carta XV, pp. 124-127.

44 A. de Morales, Apuntamientos..., cit., ff. 184r. H. DE BaEZA, Relaciones, cit, carta XVI, pp. 127-128.

45 H. DE BAEZA, Relaciones..., cit., Carta XVI, pp. 128-133.

46 A. de Morales, Apuntamientos..., cit., ff. 183v-184r. 
una parte a otra del campo. Como era de esperar don Diego no se había dado por enterado de la tentativa de última hora de don Alonso y de hecho se encontraba tranquilamente en sus viñas de Cabra donde le encontró Diego de Cárcamo, enviado por don Alonso para que requiriese su presencia en la batalla. Más aun, ni se molestó en responderle haciéndolo en su lugar Juan de Pineda quien le manifestó que don Alonso habia tomado el cartel en que don Diego le señalaba campo ante el rey de Granada y que puesto que no fue al campo de Granada en su momento no era el Mariscal obligado a ir ahora y que no hacia caso alguno de cuantas acciones llevara a cabo don Alonso. Mientras tanto en el campo de "Prado Quemado" el rey de armas repetía dos veces más los llamamientos anteriores y don Alonso esperaba en vano hasta la noche. Constatada la ausencia de su oponente se redactó el acta de los hechos debidamente atestiguada por los presentes. Se debió de arrepentir don Diego de haber desechado las razones de Diego de Cárcamo y tras pensárselo un poco estimó conveniente su presencia, no personalmente, pero si a través de un representante suyo, el mencionado Juan de Pineda, quien ya de noche apareció por el campo excusando la ausencia de su señor ante la falta de don Alonso en no aceptar los rehenes que habian acordado por darse ${ }^{4 ?}$.

Aqui se acaban los testimonios directos de los hechos, ambas partes debieron de quedar satisfechas de su posición pues habían desplegado su propaganda en menospreciar la honra de un rival que no se había presentado para defenderla. No nos consta tampoco que se verificase ningún duelo tras el nuevo ofrecimiento que les habia hecho el rey de Granada para el día 1 de septiembre. Únicamente tenemos constancia de la denuncia de Enrique IV, el 23 de agosto de ese año, del despropósito del Mariscal que había tenido la osadía de falsificar una carta en la que mostraba el permiso real para la celebración del duelo granadino todo ello con el único fin de revestir de apariencia legal lo que desde un principio le había sido denegado ${ }^{48}$.

La situación se estabilizó en los años siguientes llegándose a firmar unas treguas ${ }^{49}, 21$ de febrero de 1473 , pero de corta duración ya que los enfrentamientos continuaron al poco acompañados de una mudanza en los partidarios de uno y otro de modo que el conde de Cabra acabó aliándose con el obispo de Córdoba don Martín Alfonso y con don Pedro Venegas ${ }^{50}$. La situación posterior con la muerte de Enrique IV y la coronación de Isabel y Fernando no fue propicia a estas veleidades nobiliarias. En adelante la firmeza demostrada por los Reyes Católicos sólo permitió el ascenso de las casas nobiliarias en función de los méritos prestados al Estado y en esto estuvo hábil el conde de Cabra, quien a pesar del apoyo mostrado siempre a Enrique IV supo ver el nuevo rumbo de la política y abandonó la causa de su hija, Juana la Beltraneja, mientras que don Alonso de Aguilar no estuvo tan presto y vio menguar enormemente su influencia en la comarca cordobesa.

\footnotetext{
ibid. ff. 184r-185v

48 Archivo de los Duques de Medinaceli, Sección Histórica, 244-77.

49 H. DE BAezA, Relaciones..., cit., carta XX, pp. 137-140.

ibid, carta XXI, pp. 141-143
} 